\title{
Relative Humidity Fiber Sensor Based on Multimode Interferometer Coated with Agarose-Gel
}

\author{
Susana Novais *(D), Marta S. Ferreira $\mathbb{D}^{(0)}$ and João L. Pinto \\ I3N \& Physics Department, University of Aveiro, Campus de Santiago, 3810-193 Aveiro, Portugal; \\ marta.ferreira@ua.pt (M.S.F.); jlp@ua.pt (J.L.P.) \\ * Correspondence: novais@ua.pt; Tel.: +351-234-370-200
}

Received: 17 October 2018; Accepted: 7 December 2018; Published: 8 December 2018

check for updates

\begin{abstract}
In this work, a relative humidity (RH) sensor based on a structure with multimode interference is proposed and experimentally demonstrated. The multimode sensor is fabricated by fusion splicing a coreless fiber section to a single mode fiber. A hydrophilic agarose gel is coated on the coreless fiber, using the dip coating technique. By changing the surrounding $\mathrm{RH}$, the refractive index of the coated agarose gel will change, causing a wavelength shift of the peak in the reflection spectra. For $\mathrm{RH}$ variations in the range between $60.0 \% \mathrm{RH}$ and $98.5 \% \mathrm{RH}$, the sensor presents a maximum sensitivity of $44.2 \mathrm{pm} / \% \mathrm{RH}$, and taking in consideration the interrogation system, a resolution of $0.5 \% \mathrm{RH}$ is acquired. This sensor has a great potential in real time RH monitoring and can be of interest for applications where a control of high levels of relative humidity is required.
\end{abstract}

Keywords: fiber optics sensors; relative humidity; agarose gel

\section{Introduction}

The measurement of relative humidity $(\mathrm{RH})$ has shown to be of significant importance in a large range of applications, such as bacterial growth, process control, product quality, food and beverage processing, automotive, and meteorological industries [1,2].

Regarding sensing methods of $\mathrm{RH}$, the optical fiber sensors, in comparison to their electronics counterparts, are preferred, considering their specific advantages, such as their minimal size and low weight, immunity to electromagnetic interference, corrosion resistance, and remote sensing capability [3]. There are basically two operating mechanisms for the fabrication of fiber optic $\mathrm{RH}$ sensors. One is based on using specific technologies to form porous sensing structures, such as sputtering [4], electro-spinning [5], electron evaporation [6], or layer-by-layer nano-assembly [7,8]. The other type of RH fiber optic sensors involves using humidity sensitive coatings or gels (hydrophilic materials) on the surface or end face of the optical fiber, such as polyvinyl alcohol $[9,10]$, polyethylene glycol [11], chitosan [12,13], polyethylene oxide [14], graphene oxide [15], metallic oxide film [15,16], agar [17-20] and indium tin oxide [21,22]. This kind of polymer coatings have advantages of good performance [19], reproducibility, and long-term stability [14]. The hydrophilic materials normally swell physically and experience a refractive index change in response to change in $\mathrm{RH}$.

Different fiber sensing structures have been combined with polymer coatings. For instance, the use of fiber Bragg gratings [23], bended fibers [24], side-polished fibers [25,26], photonic crystal fibers [20,27], tapered fibers [13,15,16], Fabry-Perot cavities [28], Sagnac interferometers [29], hollow core fibers [15], and single-mode hetero-core fibers [14,30] have been proposed to detect environmental RH variations.

Agarose is considered a biopolymer, originated from a marine alga (Gracilaria Verrucosa), whose use is commonly extended in the field of biochemistry for separation of DNA chains [31,32]. The agarose gel is considered a material with desirable humid sensitivity, able to readily absorb 
and desorb water, and also to restore a fast equilibrium with atmospheric humidity. Besides that, it is extremely stable, not soluble in water and can be easily handled for device manufacture [23,31].

In this work, a multimode interferometer based on a coreless fiber coated with agarose gel is proposed for the detection of RH. The sensor is easy to produce, presents good resolution, particularly for environments with values of RH higher than $60.0 \% \mathrm{RH}$.

\section{Sensor Fabrication and Operation Principle}

The fabrication of the coated sensor, whose scheme is shown in Figure 1, involved two steps. The first step consisted on splicing a short section of coreless silica fiber (CSF, Thorlabs, Newton, NJ, USA) to single mode fiber (SMF 28e, Thorlabs, Newton, NJ, USA), using the manual mode program of the splicing machine (Fujikura $40 \mathrm{~S}$, Tokyo, Japan). The second step consisted in functionalizing the sensor with agarose gel, through dip coating technique.

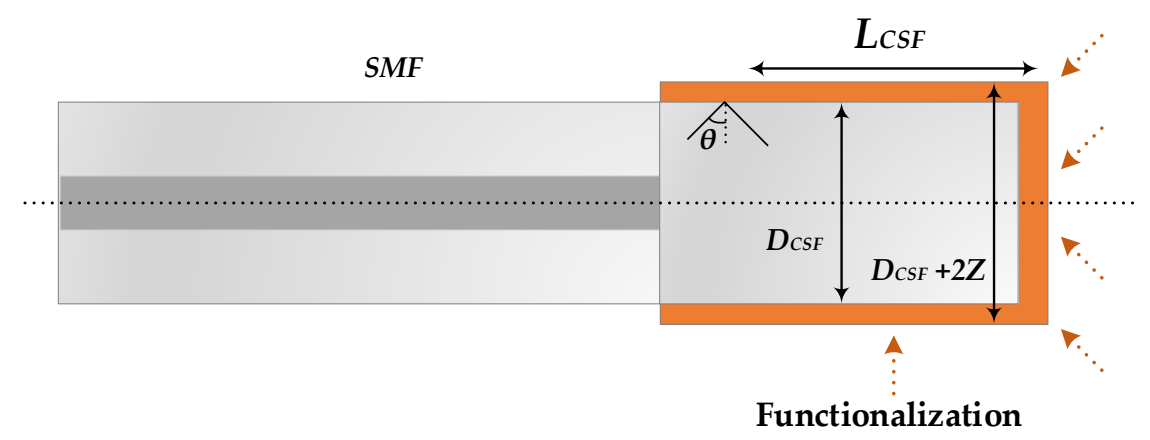

Figure 1. Schematic diagram of the sensor structure.

When the incident light comes from the SMF to the CSF, the high-order modes are excited and propagate within the CSF. These excited modes interfere with one another as they propagate along whole CSF length, giving rise to a multimode interference (MMI). According to Equation (1), the interference wavelength, $\lambda_{0}$, can be expressed by [33]:

$$
\lambda_{0}=\frac{n_{1} D_{\mathrm{CSF}}^{2}}{2 L_{\mathrm{CSF}}} p
$$

where $D_{\mathrm{CSF}}, L_{\mathrm{CSF}}, n_{1}$ and $p$ are the CSF diameter, length, refractive index, and interference number, respectively. The length and diameter of the CSF used in this work were $\sim 30 \mathrm{~mm}$ and $125 \mu \mathrm{m}$, respectively. Considering the refractive index to be 1.444 and the operation wavelength in air of $\sim 1530 \mathrm{~nm}, p$ was estimated to be 4 .

Taking into account Equation (1), there is no apparent dependence of the wavelength with the external medium. However, if one considers the evanescent field produced at the CSF/external medium interface, the diameter can be considered as an effective value of $D_{\mathrm{CSF}}+2 Z$, where $Z$ is the penetration depth. This parameter can be calculated through Equation (2) [34]:

$$
Z=\frac{\lambda_{0}}{2 \pi n_{1} \sqrt{\sin ^{2} \theta-\left(n_{s} / n_{1}\right)^{2}}}
$$

where $n_{S}$ is the surrounding medium refractive index and $\theta$ is the incident angle at the $\mathrm{CSF} /$ surrounding medium interface, as shown in Figure 1. Since the effective refractive index of the agarose gel changes with the ambient relative humidity, as the environmental refractive index changes, the propagation constants for each guided mode within the CSF will change too, which leads to shifts in the output spectra [32,35]. 


\section{Agarose Gel Coating}

The agarose solution was prepared by dissolving $0.9 \mathrm{~g}$ of agarose (BP160-100, Fisher Scientific, Pittsburgh, PA, USA) in $60 \mathrm{~mL}$ of distilled water, corresponding to a proportion of $1.5 \mathrm{wt} . \%$. The solution was then heated up to $65^{\circ} \mathrm{C}$ and a magnetic stirrer was used to dissolve the agarose in distilled water.

The sensing head was inserted in a silica capillary to ensure that the fiber was straight and stable (Figure 2). The sensor was dipped into the hot agarose solution and pulled out very fast, by moving the horizontal platform downwards. When the agarose solution cools down and reaches room temperature, it polymerizes to form hydrogel and will not assume a liquid form again unless it is heated above the melting point. The coated sensor was left to dry for $48 \mathrm{~h}$ at room temperature.

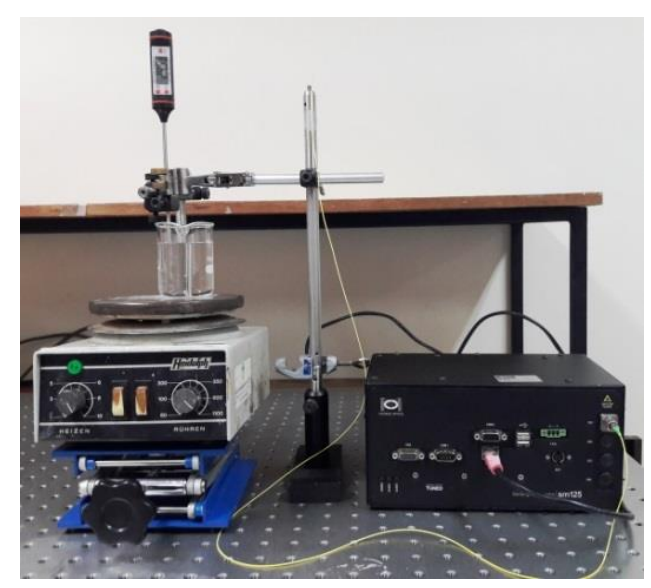

Figure 2. Photograph of the experimental setup for agarose deposition.

The agarose curing process was monitored with an optical interrogator (sm125, Micron Optics Inc., Atlanta, GA, USA, operating at $2.0 \mathrm{~Hz}$ ). The response was obtained in a spectral range between 1530 and $1570 \mathrm{~nm}$, immediately after removing the sensor from the agarose solution. This experiment was carried out in a controlled environment, with a room temperature of $25^{\circ} \mathrm{C}$. As shown in Figure 3 , there is a higher wavelength shift in the first five minutes. From that moment on until $30 \mathrm{~min}$, there is a smaller wavelength variation, which tends to stabilize after that time.

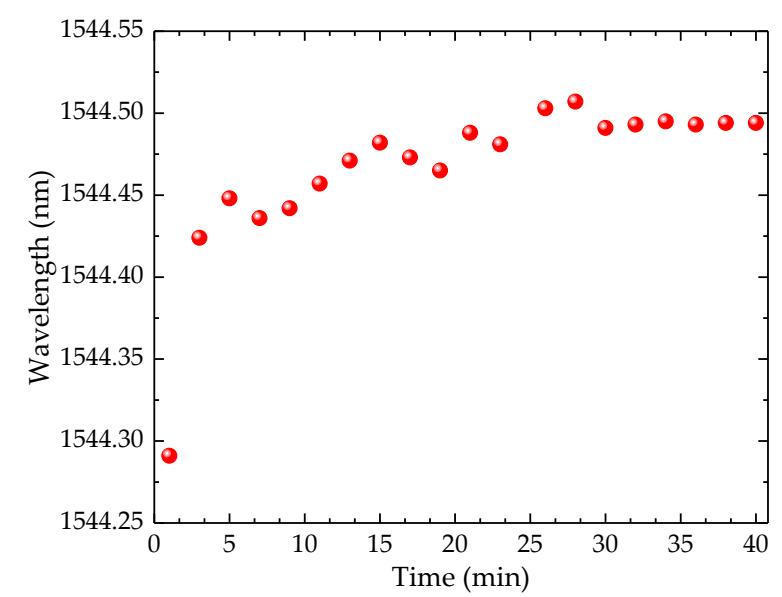

Figure 3. Peak wavelength dependence with time during the agarose curing process. 
Figure 4 shows the spectra for the sensor without agarose coating (black solid line) and with coating (red dashed line). A spectral blue shift was observed in the reflection spectrum of the device compared with its initial spectrum as shown in Figure 4. The shift in wavelength peak after coating is about $-3.59 \mathrm{~nm}$.

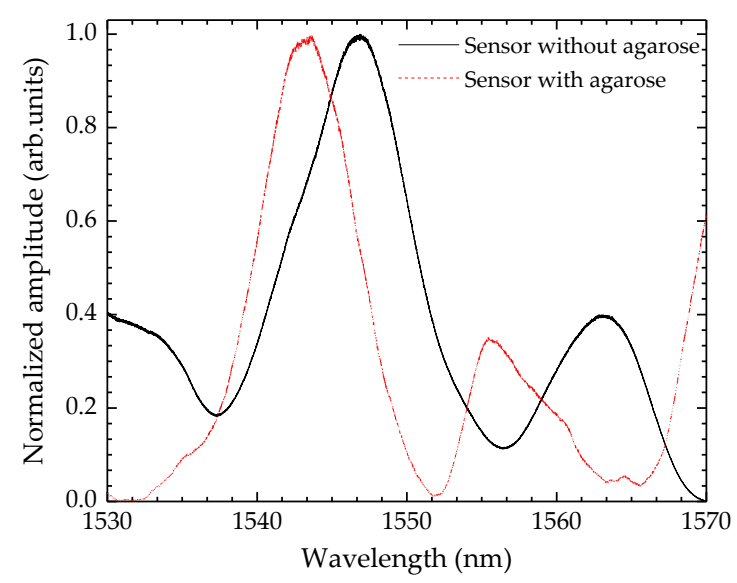

Figure 4. Sensors spectra before and after coating.

\section{Experimental Setup}

Two sensing heads, one uncoated and the other coated with agarose gel, with similar lengths $(28.8 \mathrm{~mm})$, were introduced in a thermal chamber (model Challenge 340, from Angelantoni Industrie, Cimacolle, Italy), and subjected to variations of relative humidity and temperature. The experiments in the thermal chamber were carried out simultaneously, to ensure that the sensors were exposed to the same environmental changes. This thermal chamber is equipped with a humidification-dehumidification system and a cooling-heating system that can change both RH and temperature in a controlled way. The optical fiber connector was preserved outside the thermal chamber and the reflection spectra were monitored using the interrogator sm125-500, Micron Optics Inc. (Atlanta, GA, USA), operating at $2.0 \mathrm{~Hz}$ and wavelength accuracy of $1.0 \mathrm{pm}$.

The $\mathrm{RH}$ experiments were carried out by keeping the temperature constant at $25^{\circ} \mathrm{C}$ and by varying the $\mathrm{RH}$ between $20.0 \%$ and $98.5 \% \mathrm{RH}$, while the temperature measurements were done with a constant $\mathrm{RH}$ of $60.0 \% \mathrm{RH}$ and a temperature variation between 10 and $70^{\circ} \mathrm{C}$. After each change in the parameters, a period of $30 \mathrm{~min}$ was allowed for the thermal chamber to stabilize. Figure 5 shows the scheme of the experimental setup for the characterization of the sensors.

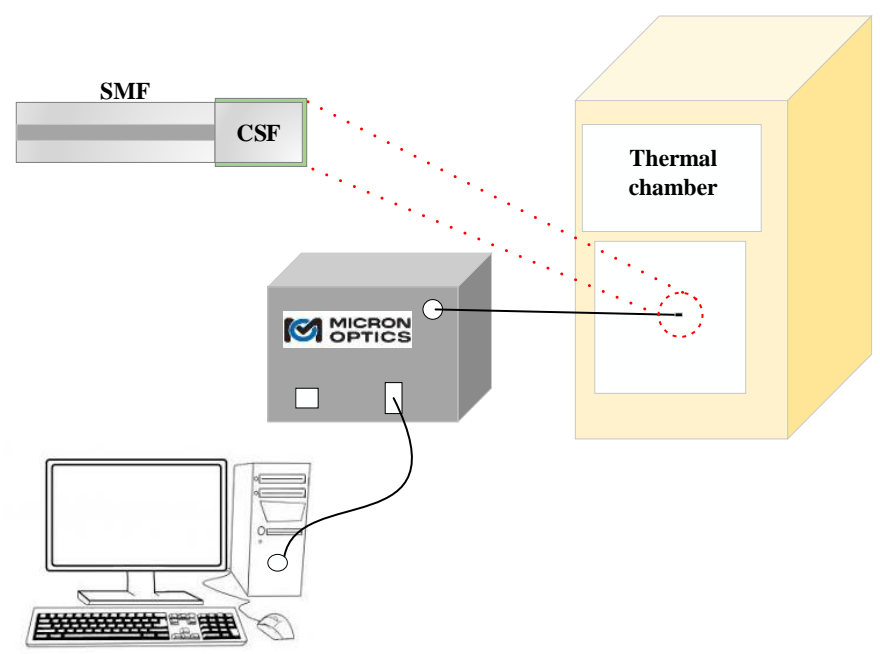

Figure 5. Experimental setup for the characterization of the sensors. 


\section{Discussion}

Figure 6 shows the wavelength shift dependence on the relative humidity for both sensors. As expected, the uncoated sensing head revealed to be insensitive to the RH variations. Although the refractive index of air depends on the $\mathrm{RH}$ [36], the variation is lower than the resolution of the proposed sensor, compromising its response. A linear fitting was adjusted to the experimental data, and a sensitivity of $0.9 \mathrm{pm} / \% \mathrm{RH}$ was attained. On the other hand, the coated sensor presented a non-linear wavelength shift towards longer wavelengths (red shift) with the external RH variations, which is more prominent for higher values of RH. This non-linear behavior has already been observed for this type of multimode interferometer sensors when subjected to refractive index variations [35], being related to the increase of the agarose gel refractive index with $\mathrm{RH}$.

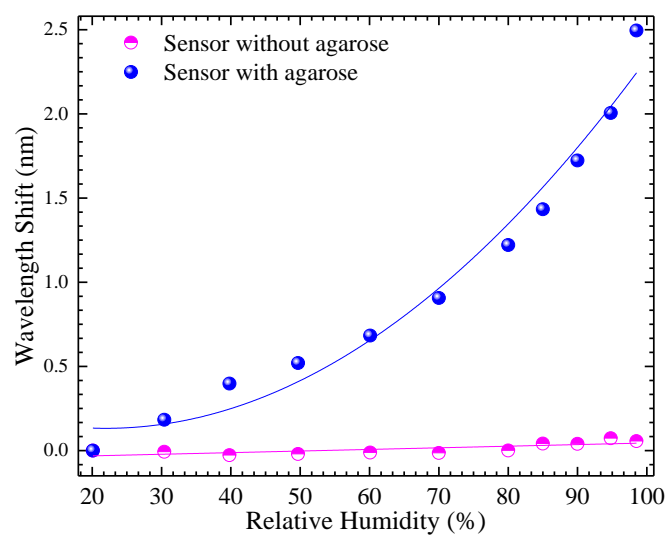

Figure 6. Measured wavelength shift dependence with relative humidity (RH), considering both sensors.

Two different linear regions were considered to estimate the coated sensor sensitivity. The first region, for lower $\mathrm{RH}$ variations, ranges from $20.0 \%$ to $50.0 \% \mathrm{RH}$, whereas the second region, for higher $\mathrm{RH}$ variations ranges from $60.0 \%$ up to $98.5 \% \mathrm{RH}$. The sensitivities attained were of $18.6 \mathrm{pm} / \% \mathrm{RH}$ $\left(r^{2}=0.988\right)$ and $44.2 \mathrm{pm} / \% \mathrm{RH}\left(r^{2}=0.922\right)$, for the first and second regions, respectively.

The temperature responses of the sensors without and with agarose were measured using the same interrogation scheme as shown in Figure 5. The temperature was raised in steps of $10^{\circ} \mathrm{C}$, from 10 up to $70{ }^{\circ} \mathrm{C}$ and $\mathrm{RH}$ was fixed to $60.0 \% \mathrm{RH}$. The response, shown in Figure 7, was linear in both cases. However, there was a drop in the sensitivity, from $13.6 \mathrm{pm} /{ }^{\circ} \mathrm{C}$ (uncoated sensor) to $7.8 \mathrm{pm} /{ }^{\circ} \mathrm{C}$ for the coated sensor. The sensor with agarose became approximately $2 \times$ less sensitive than the sensor without agarose. The cross-sensitivity between $\mathrm{RH}$ and temperature, for the coated sensor, was determined to be $0.2 \mathrm{RH} /{ }^{\circ} \mathrm{C}$.

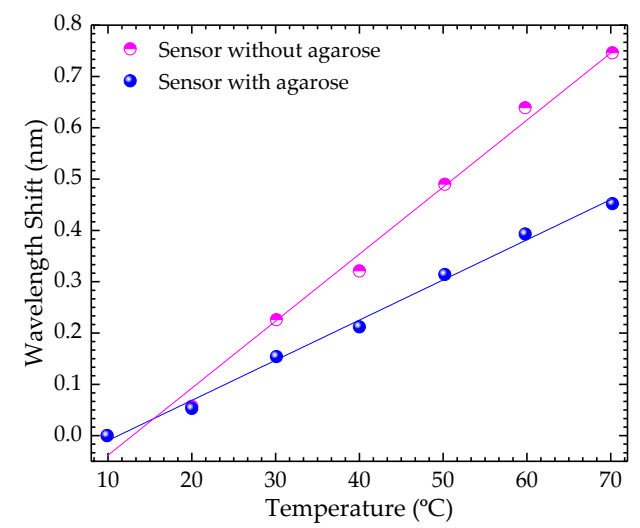

Figure 7. Response of the uncoated and coated sensors to the temperature variations. 
The coated sensor response time was evaluated through monitoring, in real time, the response when the RH of the thermal chamber was changed from $60 \%$ to $80 \%$ (Figure 8). Although the response time of the sensor is of $\sim 1 \mathrm{~min}$, it is prudent to wait at least for $5 \mathrm{~min}$ for the signal stabilization. This period is also related to the stabilization of the thermal chamber.

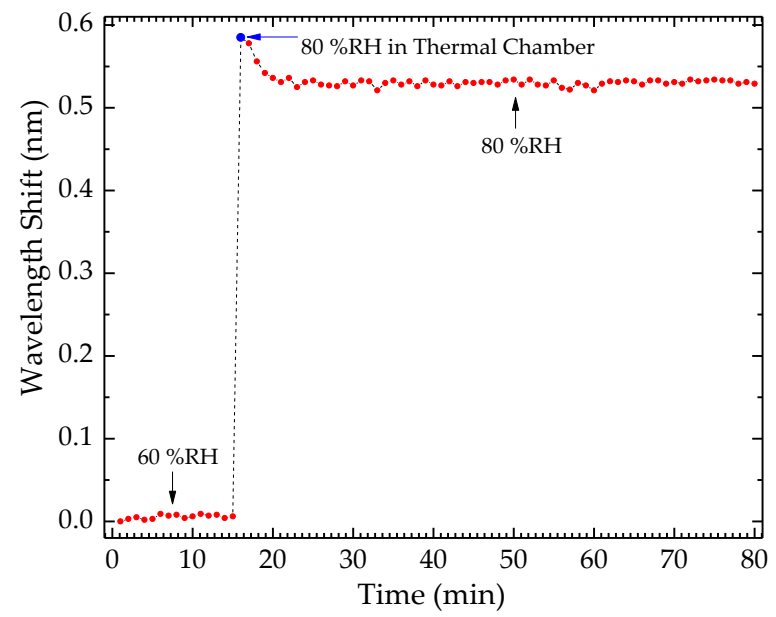

Figure 8. Response time of the sensor when subjected to a step humidity change from $60 \%$ to $80 \%$.

With reference to the stability of the projected sensor, preliminary tests were also carried out. In the future, long-term and repeatability experiments will be performed to investigate the sensor stability. The coated sensor was placed in the thermal chamber at a constant RH and temperature of $60.0 \% \mathrm{RH}$ and $25^{\circ} \mathrm{C}$, respectively. The peak wavelength was monitored during $120 \mathrm{~min}$ and the spectra were acquired once per $2 \mathrm{~min}$. The same procedure was followed for a $\mathrm{RH}$ of $70.0 \% \mathrm{RH}$ and $90 \% \mathrm{RH}$. The results are shown in Figure 9. For the first step, a mean wavelength of $1545.08 \mathrm{~nm}$ was determined, with a standard deviation of $4.7 \mathrm{pm}$. Regarding the second and third steps, the mean wavelength were of 1545.29 and $1546.11 \mathrm{~nm}$, with a standard deviation of 5.1 and $4.1 \mathrm{pm}$, respectively. It should be highlighted that during the experiment, a temperature oscillation of $0.2{ }^{\circ} \mathrm{C}$ occurred in the thermal chamber, which might have also influenced the sensor response.

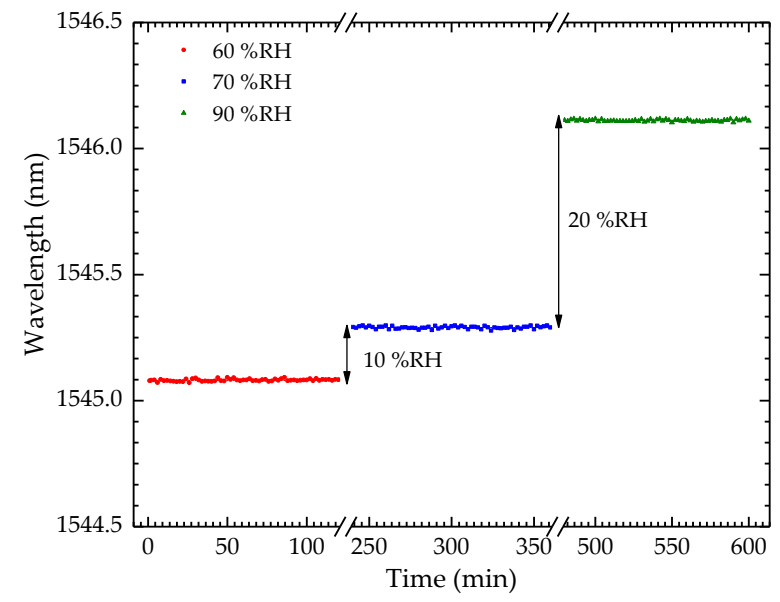

Figure 9. Step technique to estimate the resolution of the humidity sensor. 
The minimum value of humidity, $\delta_{R H}$ that the sensor is able to discriminate is given by Equation (3) [37]:

$$
\delta_{R H}=2 \frac{\sigma_{\lambda} \Delta R H}{\Delta \lambda}
$$

where $\sigma_{\lambda}$ is the maximum standard deviation of $\lambda$ for both values of $R H$, and $\Delta R H$ and $\Delta \lambda$ are the variation of RH and the mean wavelength shift between the two steps, respectively. By applying Equation (3), a resolution of $0.5 \% \mathrm{RH}$ was obtained, considering the sensor operation in the higher $\mathrm{RH}$ region. It is important to note that this value is also influenced by the spectral resolution of the equipment used for data acquisition (in this case, of $1.0 \mathrm{pm}$ ).

\section{Conclusions}

A relative humidity $(\mathrm{RH})$ sensor based on multimode interference fiber structure, coated with hydrophilic agarose gel was proposed. For comparison purposes, both an uncoated sensing structure and a coated one were subjected to the same experiments. As expected, the uncoated sensor was insensitive to the environmental RH changes. On the other hand, the sensor with agarose gel exhibited a maximum sensitivity of $44.2 \mathrm{pm} / \% \mathrm{RH}$ with a resolution of $0.5 \% \mathrm{RH}$. The proposed sensor has a great potential in real time $\mathrm{RH}$ monitoring, particularly in environments with high percentages of relative humidity. One example of such applications are the lodges where Madeira wine is stored for ageing, where the RH is usually in the range between $65.0 \% \mathrm{RH}-75.0 \% \mathrm{RH}$. However, the environment should be carefully controlled to ensure the desired quality of the product. The proposed sensor presented low manufacturing cost and easy fabrication, being an alternative to other sensors.

Author Contributions: Conceptualization, S.N. and M.S.F.; Methodology, S.N. and M.S.F.; Software, S.N.; Validation, S.N.; Formal Analysis, S.N.; Investigation, S.N. and M.S.F.; Data Curation, S.N.; Writing-Original Draft Preparation, S.N.; Writing-Review \& Editing, S.N., M.S.F. and J.L.P.; Visualization S.N., M.S.F. and J.L.P.; Supervision, M.S.F and J.L.P.; Project Administration, J.L.P.; Funding Acquisition, J.L.P.

Funding: This research was funded by ERDF funds through the Regional Operational Program of the Center and National Funds through FCT (Fundação para a Ciência e Tecnologia) under the AROMA project (CENTRO-01-0145-FEDER-031568) and by Project POCI-01-0145-FEDER-016414 PAC, cofinanced by Programa Operacional Competitividade e Internacionalização and Programa Operacional Regional de Lisboa, through the COMPETE 2020 Programme and National Funds through FCT, grant numbers BI/UI96/6643/2018 and SFRH/BPD/124549/2016.

Conflicts of Interest: The authors declare no conflict of interest.

\section{References}

1. Zhang, Z.F.; Zhang, Y. Humidity sensor based on optical fiber attached with hydrogel spheres. Opt. Laser Technol. 2015, 74, 16-19. [CrossRef]

2. Torres, D.L.; Elousa, C.; Villatoro, J.; Zubiac, J.; Rothhardt, M.; Schuster, K.; Arregui, F.J. Enhancing sensitivity of photonic crystal fiber interferometric humidity sensor by the thickness of $\mathrm{SnO}_{2}$ thin films. Sens. Actuators B Chem. 2017, 251, 1059-1067. [CrossRef]

3. Zhao, Z.; Duan, Y. A low cost fiber-optic humidity sensor based on silica sol-gel film. Sens. Actuators B Chem. 2011, 160, 1340-1345. [CrossRef]

4. Sigmund, P. Elements of Sputtering Theory. In Nanofabrication by Ion-Beam Sputtering: Fundamentals and Applications; Som, T., Kanjilal, D., Eds.; Pan Stanford: Singapore, 2012; pp. 1-40.

5. Urrutia, A.; Goicoechea, J.; Rivero, P.J.; Matías, I.R.; Arregui, F.J. Electrospun nanofiber mats for evanescent optical fiber sensors. Sens. Actuators B Chem. 2013, 176, 569-576. [CrossRef]

6. Yang, M.; Xie, W.; Dai, Y.; Lee, D.; Dai, J.; Zhang, Y.; Zhuang, Z. Dielectric multilayer-based fiber optic sensor enabling simultaneous measurement of humidity and temperature. Opt. Exp. 2014, 22, 10, 11892-11899. [CrossRef]

7. Consales, M.; Berruti, G.; Borriello, A.; Giordano, M.; Buontempo, S.; Breglio, G.; Makovec, A.; Petagna, P.; Cusano, A. Nanoscale $\mathrm{TiO}_{2}$-coated LPGs as radiation-tolerant humidity sensors for high-energy physics applications. Opt. Lett. 2014, 39, 4128-4131. [CrossRef] [PubMed] 
8. Urrutia, A.; Goicoechea, J.; Ricchiuti, A.L.; Barrera, D.; Sals, S.; Arregui, F.J. Simultaneous measurement of humidity and temperature based on a partially coated optical fiber long period grating. Sens. Actuators $B$ Chem. 2016, 227, 135-141. [CrossRef]

9. Yan, G.; Liang, Y.; Lee, E.H.; He, S. Novel knob-integrated fiber Bragg grating sensor with polyvinyl alcohol coating for simultaneous relative humidity and temperature measurement. Opt. Exp. 2015, 23, 15624-15634. [CrossRef]

10. Sun, H.; Yang, Z.; Zhou, L.; Liu, N.; Gang, T.; Qiao, X.; Hu, M. A relative humidity sensing probe based on etched thin-core fiber coated with polyvinyl alcohol. Opt. Commun. 2015, 356, 556-559. [CrossRef]

11. Acikgoz, S.; Bilen, B.; Demir, M.M.; Menceloglu, Y.Z.; Skarlatos, Y.; Aktas, G.; Inci, M.N. Use of polyethylene glycol coatings for optical fiber humidity sensing. Opt. Rev. 2008, 15, 84-90. [CrossRef]

12. Voznesenskiy, S.S.; Sergeev, A.A.; Mironenko, A.Y.; Bratskaya, S.Y.; Kulchin, Y.N. Integrated-optical sensors based on chitosan waveguide films for relative humidity measurements. Sens. Actuators B Chem. 2013, 188, 482-487. [CrossRef]

13. Chen, L.H.; Chan, C.C.; Menos, R.; Balamurali, P.; Shailender, M.; Neu, B.; Ang, X.M.; Zu, P.; Wong, W.C.; Leong, K.C. Fabry-Perot humidity sensor. Sens. Actuators B Chem. 2012, 169, 167-172. [CrossRef]

14. Wu, Q.; Semennova, Y.; Mathew, J.; Wang, P.; Farrell, G. Humidity sensor based on a single mode hetero-core fiber structure. Opt. Lett. 2011, 36, 1752-1754. [CrossRef]

15. Gao, R.; Lu, D.; Cheng, J.; Jiang, Y.; Jiang, L.; Qi, Z. Humidity sensor based on power leakage at resonance wavelengths of a hollow core fiber coated with reduced graphene oxide. Sens. Actuators B Chem. 2016, 222, 618-624. [CrossRef]

16. Liu, H.; Miao, Y.; Liu, B.; Lin, W.; Zhang, H.; Song, B.; Huang, M.; Lin, L. Relative Humidity Sensor Based on S-Taper Fiber Coated with $\mathrm{SiO}_{2}$ Nanoparticles. IEEE Sens. J. 2015, 15, 3424-3428. [CrossRef]

17. Huang, C.; Xie, W.; Yang, M.; Dai, J.; Zhang, B. Optical Fiber Fabry-Perot Humidity Sensor Based on Porous $\mathrm{Al}_{2} \mathrm{O}_{3}$ Film. IEEE Photonics Technol. Lett. 2015, 27, 2127-2130. [CrossRef]

18. Mathew, J.; Semenova, Y.; Farrell, G. Effect of coating thickness on the sensitivity of a humidity sensor based on an Agarose coated photonic crystal fiber interferometer. Opt. Exp. 2013, 21, 6313-6320. [CrossRef]

19. Bariáin, C.; Matías, I.R.; Arregui, F.J.; López-Amo, M. Optical fiber humidity sensor based on a tapered fiber coated with agarose gel. Sens. Actuators B Chem. 2000, 69, 127-131. [CrossRef]

20. Mathew, J.; Semenova, Y.; Farrell, G. Relative humidity sensor based on an agarose-infiltrated photonic crystal fiber interferometer. IEEE J. Sel. Topics Quantum Electron. 2012, 18, 1553-1559. [CrossRef]

21. Del Villar, I.; Socorro, A.B.; Corres, J.M.; Arregui, F.J.; Matias, I.R. Refractometric sensors based on multimode interference in a thin-film coated singlemode-multimode-single-mode structure with reflection configuration. Appl. Opt. 2014, 53, 3913-3919. [CrossRef]

22. Cardona-Maya, Y.C.; Del Villar, I.; Socorro, A.B.; Corres, J.M.; Matias, I.R.; Botero-Cadavid, J.F. Wavelength and phase detection based SMS fiber sensors optimized with etching and nanodeposition. J. Lightwave Technol. 2017, 35, 3743-3749. [CrossRef]

23. Lee, C.L.; You, Y.W.; Dai, J.H.; Hsu, J.M.; Horng, J.S. Hygroscopic polymer microcavity fiber Fizeau interferometer incorporating a fiber Bragg grating for simultaneously sensing humidity and temperature. Sens. Actuators B Chem. 2016, 222, 339-346. [CrossRef]

24. Mathew, J.; Semenova, Y.; Rajan, G.; Wang, P.; Farrell, G. Improving the sensitivity of a humidity sensor based on fiber bend coated with a hygroscopic coating. Opt. Laser Technol. 2011, 43, 1301-1305. [CrossRef]

25. Wang, X.F.; Farrell, G.; Lewis, E.; Tian, K.; Yuan, L.B.; Wang, P.F. A humidity sensor based on a singlemode-side polished multimode-singlemode optical fibre structure coated with gelatin. J. Lightwave Technol. 2017, 35, 4087-4094. [CrossRef]

26. Alvarez-Herrero, A.; Guerrero, H.; Levy, D. High-sensitivity sensor of low relative humidity based on overlay on side-polished fibers. IEEE Sens. J. 2004, 4, 2-56. [CrossRef]

27. Mathew, J.; Semenova, Y.; Farrell, G. Experimental demonstration of a high-sensitivity humidity sensor based on an Agarose-coated transmission-type photonic crystal fiber interferometer. Appl. Opt. 2013, 52, 3884-3890. [CrossRef] [PubMed]

28. Consales, M.; Buosciolo, A.; Breglio, G.; Irace, A.; Buontempo, S.; Petagna, P.; Giordano, M.; Cusano, A. Fiber optic humidity sensors for high energy physics applications at CERN. Sens. Actuators B Chem. 2011, 159, 66-74. [CrossRef] 
29. Chen, L.H.; Chan, C.C.; Li, T.; Shaillender, M.; Neu, B.; Balamurali, P.; Menon, R.; Zu, P.; Ang, X.; Wong, W.C.; et al. Chitosan-coated polarization maintaining fiber based Sagnac interferometer for relative humidity measurement. IEEE J. Sel. Topics Quantum Electron. 2012, 18, 1597-1604. [CrossRef]

30. Akita, S.; Sasaki, H.; Watanabe, K.; Seki, A. A humidity sensor based on a hetero-core optical fiber. Sens. Actuators B Chem. 2010, 147, 385-391. [CrossRef]

31. Xu, W.; Shi, J.; Yang, X.; Xu, D.; Rong, F.; Zhao, J.; Yao, J. Relative humidity sensor based on no-core fiber coated by agarose-gel film. Sensors 2017, 17, 2353. [CrossRef]

32. Gounaridis, L.; Groumas, P.; Schreuder, E.; Heideman, R.; Avramopoulos, H.; Kouloumentas, C. New set of design rules for resonant refractive index sensors enabled by FFT based processing of the measurement data. Opt. Exp. 2016, 24, 7611-7632. [CrossRef] [PubMed]

33. Lopez, J.E.; Guzman, A.; Arrioja, D.A.; Aguilar, R.; LiKamWa, P. Tunable multimode interference bandpass fiber filter. Opt. Lett. 2010, 35, 324-326. [CrossRef] [PubMed]

34. Fukano, H.; Kushida, Y.; Taue, S. Sensitivity improvement of optical-fiber temperature sensor with solid cladding material based on multimode interference. Jpn. J. Appl. Phys. 2015, 54, 032502. [CrossRef]

35. Novais, S.; Ferreira, M.S.; Pinto, J.L. Optical fiber tip sensor for the measurement of glucose aqueous solutions. IEEE Photonics J. 2018, 10, 6803609. [CrossRef]

36. Ciddor, P.E. Refractive index of air: New equations for the visible and near infrared. Appl. Opt. 1998, 35, 1566-1573. [CrossRef]

37. Romero, R.; Frazão, O.; Pereira, D.A.; Salgado, H.M.; Araujo, F.M.; Ferreira, L.A. Intensity-referenced and temperature-independent curvature-sensing concept based on chirped fiber Bragg gratings. Appl. Opt. 2005, 44, 3821-3826. [CrossRef]

(C) 2018 by the authors. Licensee MDPI, Basel, Switzerland. This article is an open access article distributed under the terms and conditions of the Creative Commons Attribution (CC BY) license (http:/ / creativecommons.org/licenses/by/4.0/). 